Tesis. Año 12, 11(12), 51-62

\title{
La estructura de tramas paralelas y el nacimiento del cine
}

\author{
Diego Alonso Sarmiento Herencia \\ diego.sarmiento@unmsm.edu.pe
}

\section{Resumen}

El cine es un fenómeno con muchas aristas y, por ello, muy difícil de explicar. Los procesos involucrados, los distintos elementos que juegan papeles importantes en el desarrollo de historias - personajes, imágenes, sonidos, etc.- son tantos y tan variados que pretender explicarlos o definirlos sería una tarea ociosa. Sin embargo, al analizar la obra de un individuo, se obtienen luces sobre su manera de fabricar, su artesanía, y así logramos encontrar un lugar común y la posible teorización de un proceso. Este artículo apunta a descubrir las relaciones entre cine y literatura, desde un punto de vista estructural, utilizando la historia para determinar un lugar común y nacimiento de las técnicas que conforman el cine moderno.

Palabras clave: literatura, cine, montaje, tramas paralelas, estructura.

\begin{abstract}
Cinema is a multifaceted phenomenon and, as such, is really difficult to explain. The processes involved, the diverse elements playing important parts in the development of stories — characters, images, sounds, etc. - are so many and so different that to pretend to explain or define them would be an idle chore. However, in analyzing the works of an individual artist, we find cracks from where faint lights show us how this fabrication happens; the artistry. In that way we can find a common ground gaining the possibility to theorize a process. This paper aims at discovering the relations between cinema and literature, from an structural point of view, using history to determine a common place and the birthplace of the techniques that produce modern cinema.
\end{abstract}

Keywords: literature, cinema, montage, parallel storylines, structure. 


\section{La estructura de tramas paralelas y el nacimiento del cine}

\section{Introducción}

Toda gran historia está construida sobre una gran estructura. Yendo aún más lejos, si nos fijamos bien, notaremos que todos los relatos, poemas, películas y series que gozan de cierto reconocimiento tienen en común que sus estructuras son sumamente sólidas. La estructura es cimiento, más allá del tema o los personajes, es decir, sin una extraordinaria estructura, no hay historia que se sostenga. Ahora, las formas estructurales más alucinantes son aquellas en las que todo parece fluir libremente, sin una aparente estructura porque cuando se estiran las posibilidades, cuando nos damos la oportunidad de jugar con nuevas ideas, las historias adquieren un potencia adicional que las dispara como proyectiles hacia nuevas alturas.

En el cine, la estructura, como decía Alexander McKendrick ${ }^{1}$ - "Screenplays are STRUCTURE, STRUCTURE, STRUCTURE”- es todo. Muchas veces, incluso, esta existe antes que la trama, como un esqueleto sobre la cual se inscriben elementos que conforman al final la historia. ¿Por qué es tan importante para el cine? Desde un punto de vista práctico, la estructura nos permite organizar una historia con particular economía. Desde un punto de vista comercial, nos permite mantener a los espectadores atentos a la película. Es por eso que el estudio de la estructura es importante para los cineastas y guionistas. Testimonio de esto son los innumerables libros de escritura de guion cinematográfico como Story: Substance, Structure, Style, and the Principles of Screenwriting de Robert $\mathrm{McKee}^{2}$, On Filmmaking de Mackendrick o The Hero with a Thousand Faces de Joseph Campbell ${ }^{3}$ (de donde se desprende la estructura del viaje del héroe), entre otros, que dedican gran parte de su contenido en explicar el trabajo de estructuración en la historia.

Pero, obviamente, no todo es estructura. Las diferencias entre estructura trama e historia son claves para entender la profundidad de una película. Ahí radica su poder de conectar con el público a través del tiempo. Tomemos por 
ejemplo E.T. the Extra-Terrestrial (1982) escrita por Melissa Mathison y dirigida por Steven Spielberg. A simple vista parece ser una película que trata de un extraterrestre: Luego de que un amigable extraterrestre termina atrapado en la tierra, es descubierto por un niño llamado Elliott. Él lo lleva a su casa en los suburbios donde lo presenta a sus hermanos. Todos deciden mantenerlo en secreto hasta que el extraterrestre, al que han llamado E.T. se enferma lo que fuerza la intervención del gobierno. Esto pone en aprietos a E.T. y a Elliott quien finalmente lo ayuda a escapar y a regresar a casa. La verdad es bastante distinta. Esa es la trama, más no la historia central de la película. E.T es una historia que busca una respuesta a la pregunta ¿Cómo llenar el corazón vacío de un niño que perdió a su padre? Elliott no solo consigue eso, sino que redime a la figura paterna perdida demostrando que por amor uno persiste y se entrega a sus seres queridos.

La historia prima sobre la trama y colabora en la construcción de relatos universales que trascienden al tiempo. Hasta el día de hoy, la gente disfruta de E.T. muchas veces sin saber realmente, conscientemente, de qué trata... pero lo sienten.

Mediante el contraste entre cine y narrativa, y la historia que comparten desde el nacimiento del cine, podremos establecer una relación/puente de dos vías en la que se evidenciará la retroalimentación entre ambos artes, enfocándonos en el uso de las tramas paralelas; práctica que, postulamos, inaugura el cine que conocemos hoy.

\section{De Dickens a Griffith y de Griffith a la literatura... y luego al cine}

\section{La literatura en los inicios del cine}

Los hombres hacen su propia historia, pero no la hacen a su libre arbitrio, bajo circunstancias elegidas por ellos mismos, sino bajo aquellas circunstancias con que se encuentran directamente, que existen y les han sido legadas por el pasado. ${ }^{4}$

El año pasado, 2017, se cumplieron 100 años de la Revolución Bolchevique y de todo lo que vino con ella. Además de disponer el reparto de la gran propiedad territorial, el usufructo de la tierra por parte de los campesinos y el fin a la intervención rusa en la primera guerra mundial, una de sus consecuencias más importantes fue el éxodo de cineastas que esta produjo. Pero... ¿por qué?

La necesidad de difusión de las ideas de los Bolcheviques era grande. Era imprescindible construir los cimientos sobre los que descansaría la construcción ideológica por venir. Para lograrlo, recurrieron al cine como herramienta de propaganda. Pero a falta de cineastas, debían formarlos. Entonces se funda 
el Instituto Pansoviético de Cinematografía Moscú en 1919. El Instituto Pansoviético de Cinematografía Moscú fue la primera institución en el mundo dedicada al estudio del cine y al aprendizaje de las técnicas cinematográficas.

Otra consecuencia de la revolución fue que se quebraron muchos lazos comerciales con distintos países - Bloqueo económico propiciado por los franceses y los británicos que inicia con el desembarco de sus tropas en las costas rusas del norte con el pretexto de garantizar la continuidad de la guerra contra Alemania-, resultando en una gran escasez de celuloide en Rusia. Debido a la escasez de soporte fílmico, este debía ser destinado exclusivamente a la producción de películas y no a las prácticas educativas en el Instituto. Es entonces que, guiados por el gran maestro Lev Kuleshov, muchos jóvenes del instituto emprendieron un camino pionero: el de la experimentación y teorización, sobre todo de los efectos del montaje en el entendimiento de la historia.

En la primera década del Siglo XX y al otro lado del mundo, en los Estados Unidos de Norteamérica, un joven y empeñoso dramaturgo empezaba su carrera como actor en la importante compañía cinematográfica Edison Studios. Su nombre era D.W. Griffith y, obviamente, no había sido esa su intención. Edwin Porter, productor y director en la compañía, tras rechazar un guion presentado por Griffith debido a su excesiva complejidad, le ofrece un rol en su película Rescued from an Eagle's Nest. Ya en el mundo del cine, Griffith se empieza a interesar más y más en empezar una carrera en ello. Pronto empezó a trabajar como actor para la American Mutoscope and Biograph Company y, su destino se presentó ante él. La compañía, repentinamente, tuvo la necesidad de contratar a un director nuevo, y la responsabilidad cayó sobre el joven Griffith. Como director en Biograph - como era conocida comúnmente la compañíaGriffith dirigió cientos de películas. En ellas —en colaboración con su director de fotografía, G.W. Bitzer- exploró y descubrió e inventó distintas técnicas narrativas audiovisuales, como el flash-back, las tomas y transiciones con iris, el enmascarado de sectores en la exposición y el cross-cutting. De esta etapa podemos rescatar películas como The lonely Villa (1909) o Enoch Arden (1911). En ambos cortometrajes, Griffith explora una técnica que pronto se volvería su sello y la base de lo que más adelante será el estándar de la narrativa audiovisual moderna: el cross-cutting.

En Enoch Arden, Griffith relata la historia de un náufrago que luego de diez largos años regresa a casa para encontrar a su esposa quien, creyéndolo muerto, reconstruyó su vida y está felizmente casada. La historia en la película se cuenta saltando de escena a escena entre la vida de Enoch en la isla desierta y la de su esposa, Annie Lee, esperándolo en casa. Así se construye la estructura del relato, con dos tramas que suceden en paralelo haciéndolo más dinámico y elevando el drama gracias a la simultaneidad y la comparación. Sin embargo este tratamiento no era tan novedoso. En la literatura, las historias se venían 
contando así. Y no por el hecho de que la película está basada en el poema narrativo del mismo nombre, escrito en 1864 por Alfred Tennyson. Griffith optó por hacer uso de la estructura de tramas paralelas porque conocía bien sus ventajas narrativas. Habiendo querido ser escritor a inicios del siglo XX, uno de sus principales referentes fue Charles Dickens, quien hacía uso de dicha herramienta de manera formidable. Hoy, viendo hacia atrás en la historia del cine, es fácil reconocer el uso de estructuras de tramas paralelas. Ese que en un texto escrito sería algo así: "Mientras tanto, al otro lado de la ciudad..."

¿Cómo vamos a poder contar una historia de esa manera? La gente no lo va a entender.

Bueno — dijo el señor Griffith- ¿Acaso Dickens no lo hace así?

$\mathrm{Si}$, pero eso es Dickens; es una novela; es diferente.

No tanto, esto es historias con imágenes; no es tan diferente. ${ }^{5}$

La narrativa disruptiva o narrativa no lineal es en la que los eventos son representados fuera de orden cronológico - no siguen el patrón predeterminado de estructura temporal en la que los eventos son expuestos tradicionalmenteo aparecen como tramas paralelas (inmersiones en sueños o la narración de otra historia dentro de la historia principal). Habitualmente, dicha técnica trae consigo un elemento importante en el desarrollo de suspenso en la historia: la ironía dramática.

La ironía dramática se da cuando, por ejemplo, al público se le proporciona información que el personaje principal de la escena no conoce. Puede utilizarse tanto para conseguir un efecto cómico o para generar tensión y suspenso. Un ejemplo clásico se da cerca al final de Romeo y Julieta. El público sabe que Julieta está viva, ha bebido una poción que la hace parecer muerta. Romeo, a diferencia de los espectadores, no tiene esa información y se suicida justo cuando ella está despertando. En el cine Hitchcock ejemplifica muy bien la ironía dramática en el suspenso con su ejercicio de "la bomba bajo la mesa". Él postulaba que si veíamos a una pareja sentada alrededor de una mesa debajo de la cual hay una bomba, de la cual ni ellos ni nosotros como espectadores tenemos conocimiento, y la bomba de pronto explota, eso generará un gran momento climático de sorpresa. Por otro lado, si nosotros como espectadores sabemos de la bomba, pero no los protagonistas de la escena, permaneceremos en tensión durante todo el tiempo que dure la escena, invadidos por una mezcla de temor y esperanza. Llevándolo a un ejemplo más común, a nivel narrativo, Mackendrick nos dice en su ejercicio de estructuración de guiones "Once upon a time..." que la ironía dramática aparece junto a las tramas paralelas "But meanwhile... So unbeknownst..." Dicho ejercicio está basado en la clásica estructura del cuento para niños: "Había una vez una princesa que vivía feliz en un castillo. Un buen día decidió salir a pasear sola por el bosque. Mientras tanto, sin que 
ella lo supiera, una bruja malvada entraba al bosque en búsqueda de la fuente de la eterna juventud..."

Las contribuciones de la literatura al cine no terminan ahí. En sus inicios el cine era muy parecido al teatro: secuencias contadas en continuidad con la cámara estática. La acción, entonces, se observaba desde un punto prácticamente fijo que permitía ver la escena completa. Es evidente que el cine en sus años más tiernos aún no contaba con un lenguaje audiovisual avanzado. Griffith toma también de Dickens la idea de trabajar con primeros planos. Ellos llegan para llamar la atención del espectador/lector hacia un objeto, sujeto o acción particular, gestos, reacciones... De Dickens tenemos, por ejemplo:

La tetera lo empezó. No me repitan lo que la Sra. Peerybingle dijo. Yo sé la verdad. La Sra. Peerybingle puede jurar hasta el último de sus días que es incapaz de decir cuál empezó; pero yo digo que fue la tetera ¡Yo debería saber, espero! La tetera lo empezó, 5 minutos completos antes, según el pequeño reloj holandés de la esquina, que el grillo cantara. ${ }^{7}$

Griffith, y con él todos quienes hacían cine, tomaron todo cuanto pudieron de otras artes, en particular de la narrativa. Pero un puente se puede cruzar en dos direcciones. Las ideas que nacen a partir del estudio del montaje en Rusia, aportaron ampliamente a la literatura, ayudando a construir relatos con estructuras cada vez más complejas. Recordemos a John Dos Passos con Manhattan Transfer, donde describe momentos de la vida de una serie de personas a lo largo de varios años, en un principio de manera inconexa, sin embargo, más adelante, la mayoría de las personas acaban relacionándose, de una forma u otra: matrimonios, divorcios, o simplemente por compartir el mismo espacio en un momento determinado. Ejemplo de esta técnica también aparece en su obra principal, la U.S.A. Trilogy - The 42nd Parallel, 1919 y The Big Money. La alimentación a dos vías entre la narrativa y el cine es interminable.

\section{Griffith y Eisenstein}

Volviendo a Griffith, unos años después de sus experimentos narrativos, más ambicioso y ya de manera independiente, realizó su grandioso y exitoso largometraje, The Birth of a Nation (1915) y luego, la épica pero incomprendida Intolerance (1916), ambas marcando su más grande éxito y su más terrible fracaso respectivamente.

Con esa información, crucemos nuevamente el atlántico hacia tierras bolcheviques y adelantémonos unos años, justo después de la revolución del 1917. La grandiosa — pero para nada exitosa - Intolerance, había llegado a Rusia e impactó profundamente a Lenin. Por este motivo, copias de la película 
inundaron las salas de cine. Había tantas, de hecho, que la película se convirtió en el objeto principal de estudio del Taller Kuleshov.

Cabe destacar a un participante en particular de dicho taller, un joven futuro cineasta llamado Sergei Eisenstein. Eisenstein aprovechó ampliamente las sesiones de experimentación y cuando fue su turno detrás de la cámara, demostró todo lo aprendido; joyas cinematográficas como Octubre o el Acorazado Potemkin son muestra de ello.

Vivimos en la que podría ser llamada la era de la supremacía visual. Cuando revisamos el texto de Guy Debord, La sociedad del espectáculo ${ }^{8}$, nos encontramos con la siguiente frase "Todo lo que una vez fue vivido directamente se ha convertido en una mera representación". Algo parecido es mencionado en el texto de José Luis Brea, El Tercer Umbral ${ }^{9}$ donde se discute la llegada de un tercer estadio, el de un Capitalismo Cultural, un mundo donde se negocia con identidades a través de micro políticas, donde la representación es performativa visual. Es un mundo distinto al que tuvieron enfrente los antecesores del mundo cinematográfico. Estos héroes cinematográficos, dependiendo del ángulo desde el que lo miremos, nos llevan o una gran ventaja o, quién sabe, todo lo contrario.

¿Pero por qué es importante estudiarlos? Porque es imprescindible conocer nuestro linaje cinematográfico para poder construir a partir de él.

Les voy a decir el problema con el poder científico que están usando aquí: no requirieron de ninguna disciplina para obtenerlo. Leyeron lo que otros habían hecho y dieron el siguiente paso. No obtuvieron el conocimiento ustedes mismos así que no se hacen responsables por él. Se pararon sobre los hombros de genios para lograr algo tan rápido como fuere posible y antes de siquiera saber lo que tenían lo patentaron y lo empaquetaron y lo pegaron en una lonchera de plástico y ahora lo están vendiendo, quieren venderlo ${ }^{10}$

Dichas palabras pertenecen a un diálogo del Dr. Ian Malcolm (Jurassic Park, Steven Spielberg, 1993), científico ficticio de una importante película para el panorama cinematográfico actual. Su tono de cuento cautelar es interesante y, dependiendo del punto desde donde se le mire, es o una frase muy cierta, o una exageración pues la connotación negativa de "pararse en los hombros de genios" no es necesariamente la norma. En el texto de T.S. Eliot, se discute el uso estructural de la Odisea, la epopeya de Homero, como base para la construcción de una forma nueva en el Ulises de James Joyce:

Es aquí que el uso paralelo de la Odisea por Joyce es de gran importancia. Tiene la importancia de un descubrimiento científico. Nadie antes 
había construido una novela sobre tales cimientos: nunca antes había sido necesario.

[...]

Al usar el mito, al manipular el continuo paralelo entre contemporaneidad y antigüedad, el señor Joyce está utilizando un método que otros deben usar después de él ${ }^{11}$

Borges, en su maravilloso texto "Kafka y sus precursores", también lo asevera "...cada escritor crea a sus precursores". ${ }^{12}$

Volvamos por un momento a Joyce. Hablar de Joyce es también, de cierta manera, hablar del cine. Y no nos referimos a su breve paso por el Volta — cine que ayudó a fundar y manejó en Dublin — ni a las innumerables referencias que hacen a él en distintas películas como Sunset Blvd (Billy Wilder, 1950), Lolita (Stanley Kubrick, 1997), Slacker (Richard Linklater, 1991), Husband and Wives (Woody Allen, 1992), Annie Hall (Woody Allen, 1977) o Hugo (Martin Scorsese, 2011). Para entender la conexión debemos hablar del Modernismo — vanguardia para nosotros, en Latinoamérica. Desde sus inicios estuvo fuertemente influenciado por el cine, un arte que en esos momentos aún estaba en su etapa formativa. El desarrollo de sociedades industriales modernas y el rápido crecimiento de las ciudades - así como, posteriormente, las reacciones a la Primera Guerra Mundial - están entre los factores que le dieron forma al modernismo; un movimiento de ruptura que rechaza tanto a la ilustración como a las creencias religiosas ${ }^{13}$.

Para fines de este texto, vamos a resaltar dos momentos del Ulises. El primero - que merecería una investigación aparte - es el episodio quince, conocido como Circe. Detrás de lo que aparenta ser una obra de teatro, postulo que, en realidad, existe un guion de cine. La transformación de los personajes, el elemento alucinógeno mágico de esas transformaciones, los objetos inanimados que de pronto viven y hablan. Son momentos dignos de aparecer en las más fantásticas películas animadas de Disney o en las películas del gran Georges Méliès. Lo relatado en Circe sería casi imposible de interpretar en un teatro, sin embargo en una película... el universo que construye Joyce para este episodio es deliciosamente rico en imágenes y fantasía; un tejido invisible de magia casi cinematográfica imposible de desestimar.

Otra conexión cinematográfica puede ser encontrada en Ítaca - episodio $\mathrm{XVII}$ - Elementos clásicos de comedia física aparecen cuando Bloom cae y se golpea la cabeza de manera similar a como el gran Charles Chaplin cae en su casa distintas veces en su película One A.M. (1916). Joyce entendía perfectamente la construcción de comedia y parodia. Ítaca y el resto del libro son testamento de ello. 
Estructuralmente, volviendo al tema discutido en este artículo, el Ulises es igual de maravilloso. Se vale del montaje para construir secuencias sólidas y para darnos un paseo a través de personajes, espacios y tiempo con el fin de potenciar la historia. La literatura y el cine, siempre han ido de la mano. Y deben seguir haciéndolo.

\section{Conclusiones}

¿Por qué no estudiar películas pasadas desde la estructura? ¿Por qué no construir a partir de dichas estructuras? Hacer el experimento realizado en el Ulises, construir una nueva historia, potente e inolvidable, sobre la estructura de una obra maestra del pasado. Construir sobre Lawrence of Arabia, escrita por David Bolt y dirigida por el gran David Lean (1962). Los rusos hicieron crecer el cine a partir de Intolerancia, la obra maestra de Griffith, el padre de la estructura de tramas paralelas que llevó al cine a convertirse en un arte creativo y no una objetiva representación de la realidad lineal.

Tomando en cuenta todo lo expuesto anteriormente, es evidente que el estudio de la estructura es más que necesario. El lenguaje moderno del cine necesita estar, hoy más que nunca, cerca a su tradición para poder quebrarla, hacerla florecer nuevamente. Es imprescindible.

En esa nota, cerramos este texto citando un fragmento del cuento Indoquia - escrito por el autor y en el que está basado el guion del largometraje del mismo nombre, objeto de estudio de su tesis de maestría- que es, de cierta manera, un homenaje a Dickens y a Griffith:

El silbido de la tetera fue lo siguiente que oyó. Estaba en su cama y a su lado, expectantes, estaban Ignacio y su esposa. Era de noche, pero no sabía qué hora. Preocupado intentó incorporarse para ver su reloj; Ignacio lo detuvo delicadamente. ${ }^{14}$

\section{Notas}

1 Mackendrick, Alexander. On Film-making: An Introduction to the Craft of the Director. New York, 2004.

2 MCKEE, Robert. Story: Substance, Structure, Style, and the Principles of Screenwriting. New York, 1997.

3 CAMPBELL, Joseph. The Hero with a Thousand Faces. New York 1949.

4 C. Marx y F. Engels, Obras escogidas en tres tomos, Editorial Progreso, Moscú 1981, Tomo I, páginas 404 a 498.

5 En Dickens Griffith, and the film today. Traducción hecha por el autor. Texto original: "How can we tell a story jumping about like that? The people won't know what it's about." 
"Well," said Mr. Griffith, "doesn't Dickens write that way?"

"Yes, but that's Dickens; that's novel writing; that's different."

"Oh, not so much, these are picture stories; not so different."

(Eisenstein, Sergei. Film Form, 1977, pp. 200-201)

6 Mackendrick, Alexander. On Film-making: An Introduction to the Craft of the Director. New York, 2004.

7 Escena de The cricket on the hearth (A fairy tale of home). Traducción hecha por el autor. Texto original: "The kettle began it! Don't tell me what Mrs. Peerybingle said. I know better. Mrs. Peerybingle may leave it on record to the end of time that she couldn't say which of them began it; but, I say the kettle did. I ought to know, I hope! The kettle began it, full five minutes by the little waxy-faced Dutch clock in the corner, before the Cricket uttered a chirp". Dickens, Charles (1845).

8 DEBORD, Guy: La sociedad del espectáculo. 1967.

9 BREA, José Luis. El tercer umbral. Estatuto de las prácticas artísticas en la era del capitalismo cultural. Murcia: Cendeac, 2008

10 Diálogo del Dr. Ian Malcom en Jurassic Park. Traducción hecha por el autor. Texto origi nal: 'I'll tell you the problem with the scientific power that you're using here: it didn't require any discipline to attain it. You read what others had done and you took the next step. You didn't earn the knowledge for yourselves, so you don't take any responsibility for it. You stood on the shoulders of geniuses to accomplish something as fast as you could and before you even knew what you had you patented it and packaged it and slapped it on a plastic lunchbox, and now you're selling it, you want to sell it". Jurassic Park, Steven Spielberg 1993.

11 Traducción hecha por el autor. Texto original: "It is here that Mr. Joyce's parallel use of the Odyssey has a great importance. It has the importance of a scientific discovery. No one else has built a novel upon such a foundation before: it has never before been necessary [...] In using the myth, in manipulating a continuous parallel between contemporaneity and antiquity, Mr. Joyce is pursuing a method which others must pursue after him". Eliot, T.S. Ulysses, order and myth. The Dial, November, 1923

12 Borges, Jorge Luis. Kafka y sus precursores. Otras Inquisiciones. (1952)

13 Lewis, Pericles. Modernism, Nationalism, and the Novel (Cambridge University Press, 2000). pp 38-39.

14 Fragmento de Indoquia. Sarmiento Herencia, Diego (2016)

\section{Referencias}

Eisenstein, S. (1977). Film Form (Essays in Film Theory). San Diego: Harvest Publishing.

Mackendrick, A. (2004). On Filmmaking (An Introduction to the craft of the Director). New York: Faber and Faber LTD.

McKee, R. (1997). Story: Substance, Structure, Style and the Principles of Screenwriting. New York: HarperCollins.

Marx, C. \&Engels, F. (1981). Obras escogidas en tres tomos. Moscú: Editorial Progreso. 
Dickens, C. (1845). The Cricket on the Hearth. Londres: Bradbury and Evans.

Campbell, J. (1949). The Hero with a Thousand Faces. New York: Pantheon Books.

Brea, J. L. (2008). El tercer umbral. (Estatuto de las prácticas artísticas en la era del capitalismo cultural). Murcia: Cendeac.

DeBord, G. (2000). La sociedad del espectáculo. Madrid: Pre-textos.

Borges, J. L. (1952). Otras Inquisiciones. Buenos Aires: Sur.

Lewis, P. (2000). Modernism, Nationalism, and the Novel. Cambridge: Cambridge University Press.

Eliot, T.S. (noviembre, 1923). Ulysses, order and myth. The Dial,LXXV. pp.480-83 en http://www.ricorso.net/rx/library/criticism/major/Joyce_JA/Eliot_TS.htm 